\title{
Meta
}

Journal des traducteurs

Translators' Journal

\section{The Native Language Factor in Simultaneous Interpretation in an Arabic/English Context}

\section{Saleh Al-Salman et Raja'i Al-Khanji}

Volume 47, numéro 4, décembre 2002

URI : https://id.erudit.org/iderudit/008040ar

DOI : https://doi.org/10.7202/008040ar

Aller au sommaire du numéro

Éditeur(s)

Les Presses de l'Université de Montréal

ISSN

0026-0452 (imprimé)

1492-1421 (numérique)

Découvrir la revue

Citer cet article

Al-Salman, S. \& Al-Khanji, R. (2002). The Native Language Factor in Simultaneous Interpretation in an Arabic/English Context. Meta, 47(4), 607-626. https://doi.org/10.7202/008040ar
Résumé de l'article

La présente étude cherche à confirmer ou à réfuter l'idée selon laquelle les interprètes sont plus compétents lorsqu'ils interprètent un discours oral d'une langue étrangère vers leur langue maternelle. Les données de l'étude sont constituées de deux volets : (1) un questionnaire qui montre les réponses d'un certain nombre d'interprètes professionnels ayant participé à des conférences nationales, régionales ou internationales ; (2) une analyse de la véritable prestation de quelques interprètes dans le cadre de l'exercice de leurs tâches d'interprétation dans les deux langues. Celle-ci a été faite selon quelques principaux critères comme l'adéquation linguistique, la compétence stratégique et les stratégies de la communication. Enfin, un cadre théorique base sur le modèle de variabilité (Labov 1969) a été utilisé pour valider les données. 


\title{
The Native Language Factor in Simultaneous Interpretation in an Arabic/English Context
}

\author{
SALEH AL-SALMAN AND RAJA'I AL-KHANJI \\ University of Jordan, Amman, Jordan
}

\begin{abstract}
RÉSUMÉ
La présente étude cherche à confirmer ou à réfuter l'idée selon laquelle les interprètes sont plus compétents lorsqu'ils interprètent un discours oral d'une langue étrangère vers leur langue maternelle. Les données de l'étude sont constituées de deux volets: (1) un questionnaire qui montre les réponses d'un certain nombre d'interprètes professionnels ayant participé à des conférences nationales, régionales ou internationales; (2) une analyse de la véritable prestation de quelques interprètes dans le cadre de l'exercice de leurs tâches d'interprétation dans les deux langues. Celle-ci a été faite selon quelques principaux critères comme l'adéquation linguistique, la compétence stratégique et les stratégies de la communication. Enfin, un cadre théorique base sur le modèle de variabilité (Labov 1969) a été utilisé pour valider les données.
\end{abstract}

\section{ABSTRACT}

The present research sought evidence to either support or refute the claim that simultaneous interpreters are more efficient when decoding/interpreting oral discourse from a foreign language into their mother tongue. The data for the study were collected by means of (1) a questionnaire which elicited the responses of a number of professional interpreters who participated in national, regional, and international conferences, and (2) an analysis of the actual performance of some professional interpreters in actual interpretation tasks conducted in both languages. Their performance was analyzed according to some major criteria of linguistic adequacy, strategic competence, and communication strategies. A theoretical framework based on the variability model (Labov 1969) was employed to validate the data.

\section{MOTS-CLÉS/KEYWORDS}

linguistic adequacy, strategic competence, communication strategy, variability, language dominance

\section{Introduction}

Interpretation (also called consecutive or simultaneous interpretation/ translation), like all other forms of communication, is a multi-faceted activity: it involves a sender, a channel, and a recipient. It is a form of communication between people with different linguistic and cultural backgrounds (Qian 1994: 214). The source text sender transmits a message through the source language to the interpreter, who in turn resends it through the target language to the target audience. Thus an interpreter can be viewed as a transitional point of contact between the sender and the receiver or between two languages. This task puts him in direct contact with the senders and receivers of the message at the same time to convey messages in the fastest and most efficient and effective manner. He is, moreover, expected to assess the intention of the speaker and transform what is being spoken at all levels of communication, 
including intentions and implicature. An interpreter's specific task is, therefore, to help individuals or groups, not only to understand what each other says, but also to know each other. The interpreter thus "holds a key position, if not the key position in the field of communication" (Herbert 1978: 5). Other expectations require that interpreters think fast, have strong short term memory, and be able to work under physical and mental pressure for long periods of time (Qzar, 1997).

Those of us who have had the experience of being involved in professional interpretation, at least once, have realized that the process of interpretation is a challenging task - a task that requires various types of both linguistic and non-linguistic skills: mastery of the active language, solid background of general knowledge, some personal qualities like the faculty of analysis and synthesis, the ability to intuit meaning, the capacity to adapt immediately to change in subject matter and different speakers and situations. Other qualities include the need to have good short and long term memory, the ability to concentrate, a gift for public speaking, and physical endurance and good nerves.

This study seeks to test the validity of the claim that simultaneous interpreters are better off when decoding/interpreting oral discourse from a foreign language into their mother tongue. Schweda-Nicholson (1992) has observed that numerous theoreticians agree that, within the interpretation profession, it is standard practice for simultaneous interpreters to work into their native language. What led us, as researchers, to question this practice, especially in the case of Arabic-English-Arabic interpretation, was our informal observation of conflicting evidence regarding the role of language dominance among Arabic-English bilinguals involved in interpretation. We have noticed that even when Arabic is the native/dominant language of certain interpreters, their speed of processing and the quality of their interpretation in either Arabic or English do not support the practice observed by SchwedaNicholson. In other words, control for native language dominance has not always yielded better results. We have noticed that interpretation from English into Arabic presents special problems for interpreters, despite the commonly held assumption that mastery of one's native language implies that one knows its spirit, its traditions, its source, etc., especially in terms of decoding messages. However, one should keep in mind that encoding (production) in a dominant language such as Arabic may not be as easy as decoding in it (comprehension). Lambert (1978: 134) was among the few researchers who reported that several bilingual American graduate students showed dominance in their second language over their native, mother language. His subjects were in several cases revealing a relative dominance of French or Italian over English on different tests (p. 31).

\section{Hypotheses, Objectives, and Limitations}

The present piece of research is meant to look for evidence to either support or refute the claim that simultaneous interpreters do their work more comfortably and more effectively when translating into their native/dominant language. 


\section{Data Collection}

\subsection{Sample}

A sample of ten professional Arabic-English-Arabic interpreters was chosen for this study. For our purposes, a professional interpreter was identified as one who holds a minimum of a B.A. degree in any field of knowledge and has had a minimum of five years of experience as an interpreter. The following table gives more information about the subjects, whose names will not be revealed so as to assure anonymity.

TABLE 1

Distribution of respondents in the sample

\begin{tabular}{|c|c|c|c|c|}
\hline Respondent & Sex & Degree held & Experience (in years) & Specialization \\
\hline 1 & M & BA & 10 & English Language \\
\hline 2 & M & MA & 12 & Arabic Language \\
\hline 3 & F & MA & 5 & Translation \\
\hline 4 & F & MA & 7 & Translation \\
\hline 5 & M & Ph.D. & 15 & Linguistics/Translation \\
\hline 6 & F & MA & 6 & Translation \\
\hline 7 & M & BA & 7 & English \\
\hline 8 & M & MA & 15 & English \\
\hline 9 & F & MA & 12 & English \\
\hline 10 & M & BA & 8 & Arabic \\
\hline
\end{tabular}

\subsection{Sources of Data}

The corpus of data needed for this study was obtained through (1) a questionnaire and (2) audio-recordings of simultaneous translation.

\subsubsection{Questionnaire on Language Use}

The authors prepared a 15-item questionnaire that asked the subjects to indicate which language (Arabic or English) each prefers to interpret into when considering a set of positive and negative aspects of simultaneous interpretation. The questionnaire (see Appendix, p. 29) was specially devised for this particular study. Listed below are the abbreviations of each of the 15 items that will be used in discussions of data analysis:

1. [Time Lag]

2. [Switching]

3. [Oral Fluency]

4. [Omissions]: More omission (i.e., loss of information) occurs when I interpret into ...

5. [Anticipation]

6. [Less Tension]

7. [Speed of Talk]

8. [Ease of Coping] 
9. [Memory]

10. [Resistance to Tension]

11. [Grammar]

12. [Note-Taking]

13. [Mistakes]

14. [Nonstandard Usage]

15. [Syntax]

The collected data were analyzed by a two-member team of professional interpreters, namely the authors. The questionnaire responses were tabulated and analyzed and will be discussed below. Using criteria discussed in Section 4 (below), the authors developed scales of linguistic adequacy and strategic competence in order to compare the subjects' responses.

\subsubsection{Recordings of Simultaneous Interpretation}

The recorded data were collected from actual interpretation sessions in the two languages for no less than 30 minutes in each. The available data comprised material obtained from live interpretation sessions of official meetings or conferences. The subjects covered a variety of areas including: economic, political, educational and religious topics. The tasks covered the two modes of translation: Arabic-English and English-Arabic.

Using criteria discussed in Section 4 (below), the interpreters' actual performances in the recorded data were analyzed and evaluated. There were ten sessions of one hour each, (i.e., a total of ten hours). Thus each of the ten subjects had to do a one-hour session divided between the two modes of translation.

The recorded data were collected from different people than those who did the questionnaire. In analyzing the data, the authors did not transcribe it all. The procedure they followed was to listen to the recorded material, take notes, and then transcribe selected passages to illustrate their analysis.

\section{Theoretical Background for Analysis of Data}

In this research we wanted to examine both how well the two adequacy criteria of "linguistic adequacy" and "strategic competence," discussed in Sections 4.1. and 4.2. (below), are utilized in the actual performance of interpreters. Also, how well communication strategies, discussed in Section 4.3 (below), are incorporated in the interpretation process.

\subsection{Linguistic Adequacy}

In their discussion of the performance of interpreters, Saville and Hargraves (1999:95) discuss some necessary criteria for proper interpretation. For purposes of our analysis, we have formulated the following criteria for analyzing and discussing our subjects' responses to our questionnaire and their relative success in simultaneous interpretation:

Linguistic adequacy criteria for successful interpretation

a. Semantics: accuracy of rendering meaning

b. Grammar: syntax, morphology, vocabulary 
c. Discourse: rhetorical organization, coherence, and cohesion

d. Pragmatics: sensitivity to illocution

e. Style: formal/informal

\subsection{Strategic Competence}

In addition to mastery of such matters as semantics, grammar, and style, successful interpreters must develop strategies for dealing with the information conveyed in the passages as they listen to speakers and formulate the content of their translation. For our analyses, we have formulated the following criteria for analyzing and discussing our subjects' performance in simultaneous interpretation.

\subsubsection{Strategic competence criteria for successful interpretation}

a. Interaction Skills: performance criteria

1. non-verbal features of interpretation

2. integration of reception and production through:

a. knowledge of subject matter

b. schemata/set forms

c. interpretation skills

d. experience

b. Prediction Strategies, including

1. anticipation

2. presupposition

3. etc.

c. Making-up/Compensatory Strategies, including:

1. paraphrase

2. summarizing

3. etc.

\subsection{Communication Strategies}

When an interpreter encounters problems in keeping up with a speaker, s/he may have recourse to one of several communication strategies. In order to analyze the taped simultaneous interpretations, the researchers drew upon existing taxonomies, notably these of Tarone 1981, Bialystok 1984, and Khanji 1996, and selected eight strategies that have been noted in interpretation into both Arabic and English.

\subsubsection{Communication strategies employed by simultaneous translators}

1. Skipping: Omission of unnecessary repetitions, redundant expressions or unimportant utterances which would have no place in a written version of the text.

2. Anticipation: preparation of the output in the target language into the grammatical semantic schemata of the output language.

3. Summarizing: rendering of the content in a shorter version.

4. Approximation: provision of a near equivalent term or a synonym with less precise meaning instead of the target expression.

5. Code-Switching: dialect shift from standard to informal colloquial style.

6. Literal interpretation: The use of an L2 literal equivalent of an L1 word regardless of contextual adequacy.

7. Incomplete sentences: use of fragmented utterances when interpretation is cut short in mid sentences, leaving unfinished messages. 
8. Message abandonment: periods of silence and long pauses in which certain messages are not interpreted at all due to difficulties facing the interpreter.

\section{Results}

\subsection{Analysis of Items in Questionnaire on Language Use}

\subsubsection{Analysis of Positive and Negative Factors in Language Use}

Table 2 below lists the 15-variables in the questionnaire on language use, tabulates the frequency with which each language was used in responding to the 15 questions, indicates whether the variable provided the interpreters with an advantage (positive situation) or disadvantage (negative situation) for each language, and indicates whether the question carried positive or negative implications.

TABLE 2

Advantages and disadvantages in choice of language

\begin{tabular}{|c|c|c|c|c|c|c|}
\hline \multicolumn{2}{|c|}{ Variables } & \multirow{2}{*}{$\begin{array}{l}\text { Ar. } \\
2 \\
2\end{array}$} & \multirow{2}{*}{\begin{tabular}{|} 
Eng. \\
8 \\
\end{tabular}} & \multirow{2}{*}{$\begin{array}{c}\text { Advantage } \\
\text { /Positive } \\
\text { English }\end{array}$} & \multirow{2}{*}{$\begin{array}{c}\begin{array}{c}\text { Disadvantage/ } \\
\text { Negative }\end{array} \\
\text { Arabic }\end{array}$} & \multirow{2}{*}{$\begin{array}{c}\text { Question Type:* } \\
\text { (P)ositive/ } \\
\text { (N)egative } \\
\text { P }\end{array}$} \\
\hline 1 & Adequate time lag & & & & & \\
\hline 2 & Switch mechanism & 3 & 7 & English & Arabic & $\mathrm{P}$ \\
\hline 3 & Oral fluency & 1 & 9 & English & Arabic & $\mathrm{P}$ \\
\hline 4 & More (negative) omission & 8 & 2 & English & Arabic & $\mathrm{N}$ \\
\hline 5 & Anticipation & 2 & 8 & English & Arabic & $\mathrm{P}$ \\
\hline 6 & Less tension & 3 & 7 & English & Arabic & $\mathrm{P}$ \\
\hline 7 & Fast talk & 2 & 8 & English & Arabic & $\mathrm{P}$ \\
\hline 8 & Better coping & 1 & 9 & English & Arabic & $\mathrm{P}$ \\
\hline 9 & Better memory & 4 & 6 & English & Arabic & $\mathrm{P}$ \\
\hline 10 & Resisting tension & 2 & 8 & English & Arabic & $\mathrm{P}$ \\
\hline 11 & Grammar conscious & 5 & 5 & Ar./Eng. & Ar./Eng. & $\mathrm{N}$ \\
\hline 12 & Easier note-taking & 3 & 7 & English & Arabic & $\mathrm{P}$ \\
\hline 13 & Irritating mistakes & 5 & 5 & Ar./Eng. & Ar./Eng. & $\mathrm{N}$ \\
\hline 14 & Using non-standard & 8 & 2 & English & Arabic & $\mathrm{N}$ \\
\hline 15 & More syntactic demands & 7 & 3 & English & Arabic & $\mathrm{N}$ \\
\hline
\end{tabular}

* Question type: the questions have been designed in a way for the answer to reflect a positive/negative choice of language. That is, a higher figure in the language choice box (Ar. vs. Eng.) does not necessarily carry a positive value.

An arbitrary count of respondents' choices in responding to the questions may be misleading. For example, item number 4 of the questionnaire, which reads: "More omission (i.e., loss of information) occurs when I interpret into..." is associated with "poor" choice of the language as the target language for interpretation. In this case, the language choice will reflect a disadvantage on the part of the user. Of the 15 
questions comprising the "variables" in Table 1 above, 10 questions $(1,2,3,5,6,7,8$, $9,10,12)$ were indicative of "positive" results of language choice, against five items $(4,11,13,14,15)$ reflecting "negative" results of language choice.

\subsubsection{Analysis of Responses by Individual Respondents}

Table 3 below tabulates the frequency with which each respondent chose each language in response to variables in Table 1 that are shown to have "positive" or "negative" advantages, and indicates, with a ratio, which language provides an advantage for each of the respondents. In Table, 2 we see that 10 of the 15 choices were classified as "positive" and the other 5 were "negative"; in Table 3 we have focused on the positive variables in determining which language was most advantageous for each respondent.

TABLE 3

Respondents' "positive” vs. "negative" responses on choice of language

\begin{tabular}{|c|c|c|c|c|c|c|}
\hline \multirow[t]{2}{*}{ Respondent } & \multicolumn{2}{|l|}{ Arabic } & \multicolumn{2}{|l|}{ English } & \multirow{2}{*}{\multicolumn{2}{|c|}{ Lg. Preference/Advantage }} \\
\hline & Positive & Negative & Positive & Negative & & \\
\hline 1 & 1 & 5 & 9 & 0 & Eng. & $9: 1$ \\
\hline 2 & 9 & 1 & 1 & 4 & Ar. & $9: 1$ \\
\hline 3 & 1 & 3 & 9 & 2 & Eng. & $9: 1$ \\
\hline 4 & 0 & 5 & 10 & 0 & Eng. & 10:0 \\
\hline 5 & 5 & 1 & 5 & 4 & Ar./Eng. & $5: 5$ \\
\hline 6 & 0 & 4 & 10 & 1 & Eng. & $10: 0$ \\
\hline 7 & 3 & 2 & 7 & 3 & Eng. & $7: 3$ \\
\hline 8 & 1 & 3 & 9 & 2 & Eng. & $9: 1$ \\
\hline 9 & 0 & 5 & 10 & 0 & Eng. & 10:0 \\
\hline 10 & 3 & 4 & 7 & 1 & Eng. & $7: 3$ \\
\hline \multirow[t]{2}{*}{ Total } & 23 & 33 & 77 & 17 & & \\
\hline & 56 & & 94 & & & \\
\hline
\end{tabular}

As the table shows, the choice of Arabic positively was recorded by one respondent only (No. 2). Meanwhile, 8 respondents chose English for that matter, and one respondent (No. 5) showed a balanced use of the two languages in the process of interpretation.

The table also shows that the total number of responses in which the subjects opted for Arabic as the preferred language of their choice was 56 for all 10 respondents. Twenty-three of them were classified as "positive" and 33 as "negative." On the other hand, the responses which opted for English reached a total of 94, distributed as follows: 77 were marked as "positive" and 17 as "negative."

\subsubsection{Analysis by Adequacy Criteria}

Table 4 indicates whether each item in the questionnaire represents a criterion of linguistic or strategic adequacy as described in Section 4.1. The 15 items of the ques- 
tionnaire fall into two divisions: 8 items reflect linguistic adequacy on the part of the interpreter's skills, and 7 items reflect strategic competence.

TABLE 4

Analysis of linguistic and strategic criteria in language use

\begin{tabular}{|l|l|l|c|}
\hline Item No. & Statement of Item & Adequacy Criteria & $\begin{array}{c}\text { Lg. Choice Assessment: } \\
(\mathrm{P}) \text { ositive/(N)egative }\end{array}$ \\
\hline 1 & Adequate time lag & Strategic & $\mathrm{P}$ \\
\hline 2 & Switch mechanism & Strategic & $\mathrm{P}$ \\
\hline 3 & Oral fluency & Linguistic & $\mathrm{P}$ \\
\hline 4 & More (negative) omission & Linguistic & $\mathrm{P}$ \\
\hline 5 & Anticipation & Strategic & $\mathrm{P}$ \\
\hline 6 & Less tension & Strategic & $\mathrm{P}$ \\
\hline 7 & Fast talk & Linguistic & $\mathrm{P}$ \\
\hline 8 & Better coping & Strategic & $\mathrm{P}$ \\
\hline 9 & Better memory & Strategic & $\mathrm{N}$ \\
\hline 10 & Resisting tension & Strategic & $\mathrm{P}$ \\
\hline 11 & Grammar conscious & Linguistic & $\mathrm{N}$ \\
\hline 12 & Easier note-taking & Linguistic & $\mathrm{N}$ \\
\hline 13 & Irritating mistakes & Linguistic & $\mathrm{N}$ \\
\hline 14 & Using non-standard & Linguistic & Linguistic \\
\hline 15 & More syntactic demands & & \\
\hline
\end{tabular}

The results obtained from Tables 2, 3 and 4 above show clearly that the greatest majority of respondents were more comfortable when interpreting from Arabic into English. The statistical data reflect a clear tendency among English-Arabic-English interpreters to opt for Arabic-into-English tasks rather than the opposite.

The previous findings run counter to the hypothesis that simultaneous interpreters are better off when decoding/interpreting oral discourse from a foreign language into their mother tongue. Thus, the claim that it is a standard practice for simultaneous interpreters to work into their native language has been rightly challenged.

\subsubsection{Analysis of Respondents' Language Choice on the Basis of Adequacy Criteria}

As we indicated earlier, it is not always easy to draw a line between the two criteria of linguistic adequacy and strategic competence since the two are interrelated and the control of one depends very much on the mastery of the other. Nonetheless, we listed seven items in the questionnaire, namely items $1,2,5,6,8,9,10$ as pertaining to strategic competence, with the other eight items, namely $3,4,7,11,12,13,14,15$, pertaining to linguistic adequacy. 


\subsubsection{Linguistic Adequacy}

As indicated in 4.1., this category entails a set of variables including the semantic, grammatical, discoursal, pragmatic, and stylistic. For purposes of this particular study, we subjected the elicited data to all five variables, but we place more emphasis on the semantic component as it has more bearing on meaning than the other four. There are degrees of accuracy in rendering meaning, however, which vary according to some additional criteria of grammaticality, together with some discoursal, pragmatic, and stylistic criteria. Table 5 tabulates the frequency with which the respondents indicated that they preferred to interpret into Arabic or English when each of the 8 items in Table 4 representing linguistic adequacy was involved.

TABLE 5

Language choice for linguistic competence items

\begin{tabular}{|c|c|c|}
\hline \multirow{2}{*}{ Item No. } & \multicolumn{2}{|c|}{ Language Choice } \\
\cline { 2 - 3 } & Arabic & English \\
\hline 3 & 1 & 9 \\
\hline$\star 4$ & 8 & 2 \\
\hline 7 & 2 & 8 \\
\hline 11 & 5 & 5 \\
\hline 12 & 3 & 7 \\
\hline 13 & 5 & 5 \\
\hline$\star 14$ & 8 & 2 \\
\hline$\star 15$ & 7 & 3 \\
\hline
\end{tabular}

* The language choice is here indicative of a negative value.

\subsubsection{Strategic Competence}

The strategic competence criteria comprised the interaction skills of performance criteria such as: integrating reception and production and the non-verbal features of interaction. Table 5 tabulates the frequency with which the respondents indicated that they preferred to interpret into Arabic or English when each of the 7 items in Table 4 representing strategic competence was involved.

TABLE 6

Language choice for strategic competence items

\begin{tabular}{|c|c|c|}
\hline \multirow{2}{*}{ Item No. } & \multicolumn{2}{|c|}{ Language Choice } \\
\cline { 2 - 3 } & Arabic & English \\
\hline 1 & 2 & 8 \\
\hline 2 & 3 & 7 \\
\hline 5 & 2 & 8 \\
\hline 6 & 3 & 7 \\
\hline 8 & 1 & 9 \\
\hline 9 & 4 & 6 \\
\hline 10 & 2 & 8 \\
\hline
\end{tabular}


The questionnaire results showed that the strategic competence criteria for the ten positive values associated with language choice, Arabic or English, were in favor of English as follows:

The results obtained from Tables 5 and 6 above show an obvious tendency towards choosing English. Items 3, 7, 12, indicate that English was chosen positively by the interpreters as the language which provides them with a better linguistic facility in the process of interpretation. And whereas items number 11 and 13 showed a balanced performance as far as language choice is concerned, items 4, 14, and 15 showed that the extra use of Arabic is being associated with a negative value which hampers the process of interpretation.

\subsubsection{Comparison of Data in Tables 4-6}

The questionnaire incorporated 8 questions which fed into the linguistic adequacy criteria (see Table 4 ). Three of the eight items $(3,7,12)$ showed a positive assessment of language choice, the other three items $(4,14,15)$ showed a negative assessment of language choice, and items 11 and 13 showed a balanced performance. Items (3, 7, 12) which reflected a positive choice of the language favored English with a 9:1, 8:2, 7:3 ratio. Items number 11 and 13 showed a balanced language choice of 5:5 ratio.

The analysis then suggests that more oral fluency, fewer omissions, easier notetaking, more use of standard, more syntactic accuracy, and fewer irritating mistakes were detected. In other words, the interpreters showed a positive tendency towards interpreting from Arabic into English and not vice versa, with English being the target language.

As shown in Table 4, seven of the 15 questionnaire items were oriented towards detecting the strategic competence among interpreters. And as Table 6 shows, the seven items $(1,2,5,6,8,9,10)$ scored a ratio of $8: 2,7: 3,8: 2,7: 3,9: 1,6: 4,8: 2)$ for English: Arabic, respectively. This shows clearly that the general trend favored interpreting from Arabic into English, with English being the target language. Apparently, issues pertaining to time lag, switch mechanism, anticipation, less tension, better coping, and better memory were more adequately handled when interpreting from Arabic into English.

\subsection{Analysis of Simultaneous Interpretation}

Whenever an interpreter embarks on interpreting either into a native or foreign language, he may encounter many of the difficulties that evoke adjustments in speech. These adjustments may result in successful or unsuccessful interpretation into the target language. Paraphrasing, summarizing, synonymy, approximation, anticipation... are examples of those adjustments.

In recent years, there has been a growing interest among researchers in the analysis of communication strategies employed by either interpreters or foreign language learners as they seek to convey messages through the target language. Tarone (1981: 285) defines communication strategies as "a speaker's attempt to communicate meaningful content in the face of some apparent deficiencies [...] .” Ellis (1984) suggested that the notion of communication strategy could be a useful one for evaluating communicative performance. We will, therefore, make use of this notion in order to describe the quality of the simultaneous interpretation data collected, which 
is based on English-Arabic and Arabic-English oral performances of ten Arab bilingual interpreters. The 10-hour audio-recordings were analyzed by the researchers in order to detect and identify the communication strategies employed in both Arabic and English by each interpreter. Our analysis comes very close to monitoring the interpretation process rather than simply studying the product. The aim of the analysis, therefore, is to determine problematic areas facing the interpreters in the target language in order to identify the strategies utilized, and consequently to see if the interpreters were successful or not in overcoming interpretation difficulties. After identifying the strategies, we will contrast them in terms of successful (achievement) and unsuccessful (reduction), strategies. Below is a discussion and definitions of the strategy types that were found in the study.

\subsubsection{Communication Strategies}

In order to identify a communication strategy, we had to mark and then label relevant parts of the data that demonstrated a noticeable communication problem and observe how the interpreter dealt with it in his/her attempt to seek alternative ways to overcome the problem and communicate meaning to the audience. The modified taxonomic format of strategies developed for the analysis in the present study draws upon some of the existing taxonomies, notably those of Tarone 1981, Bialystok 1984, and Khanji 1996, among others (see section 4.3 above). The eight most frequently used strategies in both Arabic and English interpretation were:

1. Skipping: An interpreter uses this strategy by leaving out unnecessary repetitions, redundant expressions or unimportant utterances which would have no place if the original text were written.

2. Anticipation: Using this strategy, an interpreter anticipates what will come next and prepares appropriate output in the target language. It is a strategy in which the interpreter manages to transform the organization of information by immediately entering it into the grammatical and semantic schemata of the output language, in some cases before the speaker has uttered the anticipated word or phrase. These "anticipations" are something like set phrases which carry much of the informational content of the message.

3. Summarizing: This strategy is one that an interpreter may use in coping with long sentences by reducing them to a minimum while preserving the content of the message. In doing so, interpreters manage to achieve an economic means of expression.

4. Approximation: An interpreter uses this strategy to provide a near equivalent term or a synonym with less precise meaning in an attempt to interpret a target expression.

5. Code-switching: This strategy refers to style shift from standard to informal colloquial Arabic. Interpreters resort to this strategy when they cannot cope with time pressure when the speaker talks fast and gets ahead of the interpreter.

6. Literal interpretation: With this strategy the interpreter simply uses an L2 literal equivalent of an L1 word irrespective of contextual adequacy.

7. Incomplete sentence strategy: This strategy results in fragmented utterances when interpretation is cut short in mid-sentence, leaving unfinished messages. This strategy occurs when the interpreter takes too much time trying to find equivalent expressions but fails to do so before additional input must be interpreted.

8. Message abandonment: When an interpreter uses this strategy, periods of silence and long pauses occur in which certain messages are not interpreted at all because of difficulties facing the interpreter. 
Table 7 gives an analysis of how the above strategies were used by interpreters in the present study. The occurrence of each strategy more than 10 times in the target output language by all interpreters was considered of a high frequency, whereas the occurrence of the strategy 5 or fewer times was considered of a low frequency. For instance, message abandonment was the most frequently used strategy when interpreting into Arabic since it occurred more than 10 times and consequently it has a high frequency of occurrence.

The 8 strategies listed in Table 7 below are classified according to their effectiveness in achieving positive equivalent informational transfer. For example, the first strategy reflects the highest degree of transfer whereas strategy number 8 falls short of achieving the goal or misses it altogether.

TABLE 7

Frequency of Communication Strategies in English/Arabic Interpretation

\begin{tabular}{|c|l|c|c|}
\hline No. & Type of Strategy & $\begin{array}{c}\text { Interpretation } \\
\text { into Arabic }\end{array}$ & $\begin{array}{c}\text { Interpretation } \\
\text { into English }\end{array}$ \\
\hline 1. & Skipping & low & high \\
\hline 2. & Anticipation & high & low \\
\hline 3. & Summarizing & low & high \\
\hline 4. & Approximation & high & high \\
\hline 5. & Code-switching & high & low \\
\hline 6. & Literal interpretation & high & low \\
\hline 7. & Incomplete sentences & high & none \\
\hline 8. & Message abandonment & high & low \\
\hline
\end{tabular}

As Table 7 shows, "skipping" has been classified as the most favorable strategy since it reflects the interpreter's ability to make relevant omissions which leave out unnecessary repetitions, redundant expressions and the like. On the other hand, "message abandonment" (No. 8) suggests periods of silence and long pauses which result in important omissions in the interpretation of the SL content.

\subsubsection{Direction of Interpretation}

\subsubsection{English to Arabic}

\section{A. Achievement strategies}

Anticipation and approximation strategies were used when interpreting into Arabic. These two strategies are the only instances of an achievement-type strategy employed in Arabic interpretation. Achievement strategies, according to Khanji et al. (2000), are strategies in which speakers make an effort to retrieve the target expressions, and thus achieve a solution to a communicative problem they face. Therefore, Arab interpreters managed to successfully anticipate various messages in advance by immediately organizing information in the output language. They succeeded in anticipating particularly culture-specific expressions by actually saying them before speakers had uttered the corresponding expressions. They were also able to predict the appearance of expressions that frequently occur together in speech before they unfold. 
Approximation was another achievement strategy used in Arabic interpretation. We will provide some instances of this strategy in the following section when we analyze interpretation into English. Interpreters resorted to approximation by replacing structures or expressions by others with which they shared some semantic features. The implications of using these two achievement strategies will be analyzed later in our discussion of language variation.

\section{B. Reduction Strategies}

The most widely used strategies that have a higher frequency of occurrence when translating from English to Arabic were: message abandonment, literal interpretation, incomplete sentences, and code-switching. This observation clearly indicates that interpreters working into Arabic employed more reductionist-type of strategies on the average. Reduction strategies, according to Khanji et al. (2000), are "attempts to avoid a communicative problem without being able to develop an alternative plan," and in this case the original communicative goal of interpretation is not achieved.

The following examples clearly show both distortion and lack of interpretation in three types of reduction strategies.

1. Message abandonment: The example below shows no speech strategy. The interpreter here started to interpret but quickly gave up to render the message in Arabic and this consequently caused interpretation breakdown.

"On this day in the desert of this great rift valley, the people of Jordan stepped out of the shadows of strife."

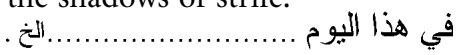

2. Literal interpretation: The examples below show that the interpreters have treated the English words as if they have already been borrowed into Arabic with minimal phonological and morphological adjustment.

- the hard stony soil

- the tools of peace must be picked up

- you have made a great choice

- to establish a future of tranquility and peace to your children:

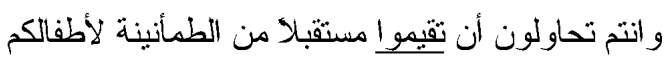

3. Incomplete sentences:

- signatures on a document did not mean that they automatically produce changes of such magnitude.

الخ .

التوقيع على وثائق لا بعني تلقائيا

As for code-switching, interpreters resorted to this strategy, which is a type of a short-cut or an easy way out to use the informal form of Arabic instead of the demanding standard Arabic. Interpreters employed this strategy by summarizing messages they failed to interpret earlier in the standard form of the language. Summarizing in informal Arabic, as we have pointed out, seems to have freed the inter- 
preters from the linguistic constraints and the conscious monitoring of standard Arabic which can be quite demanding, as we will later explain when discussing the significance of use of this strategy in relation to oral language proficiency.

It is observed, therefore, from such examples of strategy use that there was a breakdown of performance in communicating the messages to audience due to apparent insufficient linguistic sources in Arabic interpretation.

\subsubsection{Arabic to English}

A different picture emerges when we look at strategy types employed when interpreting into English. First of all, the reduction strategies found in Arabic interpretation did not appear in English interpretation, and their occurrence here was frequently low. There were no instances of incomplete sentence strategy employed by any interpreter, whereas the same interpreters resorted to this and other reduction strategies quite often when interpreting from English into Arabic as we have already pointed out. Secondly, achievement strategies such as approximation, skipping and summarizing were found to have a high frequency in English interpretation. For instance, the following Arabic expressions were approximated, though in a less precise way, in English.

- establish prayer (instead of "perform")

- encourage people to marry (instead of "urge")

- to make the Moslem afraid (instead of "deter" or "curb")

- indecent boys (instead of "illegitimate")

As for skipping, interpreters here omitted some redundant items and concentrated on more important ones only when they felt that omissions may not have affected interpretation. It was clear that omissions that occurred in skipping, were not due to great information load, time pressure or inability to process information quickly. It was perhaps due to the redundant use of lexical Arabic items or synonyms, a linguistic feature of Arabic style.

Summarizing was employed more in English interpretation than in Arabic. It seems that in order to cope successfully with long Arabic sentences, the interpreter employed such a strategy which ultimately led to achieving an economic means of expression while preserving the content of a message.

To conclude this section, we are inclined to interpret the quality of interpretation in terms of strategy difference. There is evidence to show that interpreters working into English employed more achievement strategies than reduction strategies. English interpretation, in general, did not cause much trouble for interpreters expressing themselves competently and gracefully. Speed, i.e., automaticity of performance in English interpretation was not marked by overt hesitational features in their communicative behavior. That is, their oral production did not lack speed or facility in retrieving words that met the requirements of the task (rapid-word retrieval) as often as was the case in their Arabic interpretation.

Strategy difference, therefore, provides another piece of evidence that interpretation from English to Arabic is more problematic according to the data analyzed in this study. 


\section{Summary and Discussion}

\subsection{Summary of analysis of questionnaire on adequacy criteria}

The results obtained from the sections on adequacy criteria (5.1.3-5.1.4.2, Tables 46) were in favor of interpreting from Arabic into English. The statistical data concluded from the 15-item questionnaire (8 reflecting linguistic adequacy and 7 reflecting strategic competence) were equally supportive of the Arabic-into-English choice of most subjects comprising the sample. Of course, all five variables of linguistic adequacy were considered (see section 5.1.4.1.). Similarly, the strategic competence criteria of integrating reception and production together with the non-verbal features of instruction (section 5.1.4.2.) showed an obvious tendency towards interpreting from Arabic into English.

It is important to point out, however, that the two adequacy criteria stated above are inseparable. Consequently the inadequate mastery of the two types of competence was shown among the majority of the interpreters when interpreting from English into Arabic, for those interpreters failed to have a good control in these two types of criteria.

\subsection{Summary of analysis of actual interpretations}

The results of this section may be summed up in the following:

- Very few interpreters showed a balance of their two languages in the process of interpretation, but the majority of interpreters reacted more positively (in their responses) towards English.

- Not all of the "achievements" are equal nor are all the "reductions." The four achievement strategies identified in section 5.2.1. above were ranked as follows: skipping, anticipation, summarizing, and approximation. The reduction strategies showed that "code-switching" was the least damaging, followed by literal interpretation, incomplete sentence strategy, and then message abandonment as the most harmful.

- Most interpreters involved in English-Arabic interpretation resorted to more use of reduction-type rather than achievement-type strategies.

- The standard Arabic used by almost all interpreters showed poor performance due to various factors such as familiarity with the subject matter, speaker's speed, skill, etc. This was shown clearly when they frequently resorted to employing a strategy of summarizing informally in colloquial Arabic rather than in the elevated highly polished standard Arabic. Obviously the three varieties of Arabic, namely colloquial, "standard," and classical Arabic are not the same or quite similar phenomena. Colloquial Arabic is what native speakers begin developing as they acquire language, and it serves as the medium for most spoken interaction throughout life. Standard Arabic (English, etc.) is learned rather than acquired. Consequently, oral production of colloquial language is in a sense "more automatic" and more natural than oral production of a "standard" variety.

Interestingly, most of the code shifts occur when the speaker was reading from a written text. Written texts tend to use more sophisticated vocabulary, more complex syntax, and more complex semantic and pragmatic implicatures than even rather formal oral discussions, including those conducted in "standard' language in formal settings. 
Educated people may be able to use more "standard" (or "high register") language in professional discussions orally than the average person on the street, but they will also include some of the "clutter" that is omitted when a good interpreter invokes the strategy of skipping. One function of this clutter is to provide the speaker with a bit of "thinking time" as s/he formulates what is to follow. In this connection, our instances of skipping occurred with extemporaneous oral delivery rather than with the reading of a tightly organized written text. For example, if we, the authors, carry on a conversation about, for instance, linguistic theory, we will probably choose to use colloquial communication strategies, but if we are having the "same" conversation with a visiting lecturer (whether in Arabic or English), we will shift to the communication strategies that one associates with the use of "standard" language.

Classical Arabic is yet something else. It is basically not a "spoken language." Two imams will not carry on an everyday conversation with classical Arabic syntax and vocabulary. The best they could do is sprinkle classical words and phrases throughout a colloquial or "standard" discourse analogous to what we have described above in our reference to the two of us. Most of the code shifts from classical to colloquial occurred with readings of written texts with syntax and vocabulary that are even more complex than what one would find in the above-mentioned discussion of linguistics with a visiting scholar in a "standard" variety of language.

Interpretation from English into Arabic was manageable by some interpreters when interpreting religious texts. Their performance was, consequently, better when the subject matter was familiar, an indication that their good control of the language, style, and content was determined by the nature of the interpretation task as well (i.e., the subject matter).

Based on these results, two observations emerge: First, the interpreters' oral language system in Arabic showed some type of variability especially when interpreters were able to employ both reduction and achievement strategies. Resorting to these two kinds of strategies was determined by the nature of the interpretation task, which seems to have influenced the choice of either successful or unsuccessful strategies. Second, the poor control of language use in the dominant language as well as the good control of it was evident in various contexts. That is, the variable system of their dominant language showed changes when the linguistic environment changed. For instance, familiar subject matter such as that found in religious texts produced high quality of interpretation in the dominant language (a good language control), but this was not the case in political or economic subject matters (poor language control).

\subsection{Labov's Variability Model}

We assume that the Arab interpreters cannot be said to have a homogeneous competence, which applies a Chomskyan paradigm for formulating a theory about the nature of language as a hypothetical entity. In other words, the Arab interpreters do not necessarily possess sociolinguistic knowledge as perfect as their colloquial native Arabic, since the study findings clearly showed some deficiencies in their linguistic and strategic competence. A varying or a heterogeneous competence (differing abilities) is made up of various levels of proficiency ranging from weak to native proficiency, i.e., following Labov (1969). It is made up of a continuum of styles ranging 
from the vernacular (colloquial), or (unattended speech) to the most careful monitored speech. We have already reported how in the case of our respondents, the language problems which affected meaning were mainly related to too much attention paid to terminology and a focus on lexical choice in interpretation. We have already pointed out also that some interpreters failed to render the appropriate TL lexical equivalents in classical Arabic and that, in turn, affected meaning negatively.

Although the dominant language of the interpreters included the two forms of Arabic, i.e., the classical and the colloquial, the two forms pose different kinds of challenges for interpreters. The interpreters failed to express themselves properly in classical Arabic when they paid the least attention to Arabic forms, and had to resort to colloquial Arabic forms when they faced communicative problems in the form of Arabic, i.e., standard Arabic, they were supposed to employ during interpretation. Variability in the interpreters' dominant language is, therefore, evidenced in their language behavior that seems to have been caused by the degree of attention which interpreters paid to language forms (i.e., written and spoken registers) when they faced interpretation problems.

The interpreter's dominant language is made up of two systems: first, a metalinguistic knowledge system, which Krashen (1981) terms knowledge of the monitor; the monitor is learned and is accessible to conscious introspection and may be described by the interpreter in terms of consciously formulated grammatical rules (evidenced in the prestige classical Arabic form). The second system, which Arab interpreters (as well as other Arab speakers) resort to when they face difficulties expressing themselves in classical Arabic, is the implicit knowledge which consists of the unconscious competence they have as a result of acquiring, through natural processes of social interaction since infancy, the ability to speak and understand Arabic, and with which they have better fluency and facility in communication. However, fluency in classical Arabic will be weak if certain conditions are not met for the monitor to work, that is, if the interpreter has not maintained familarity with this register. As a matter of fact, what applies to second language learners when they monitor their second language appears to apply also to interpreters employing classical Arabic in interpretation. That is, Arab interpreters may perform well in classical Arabic when they have time to monitor their language but are less successful when the speaker's delivery does not allow them to recall what they have learned about classical Arabic. Under these conditions, which are based on Krashan's (1981) work, Arab interpreters may do well in interpretation when they have enough time to monitor and when they consciously know the grammar rule in question. On the other hand, their performance will be considered as poor when they resort to the low form of Arabic - and they did so, as the data show-when they were pressured by the fast talk of the speaker and could not cope, consequently resorting to the strategy of summarizing informally by not using strictly classical Arabic. The code-switching phenomenon, as a strategy employed by interpreters is, therefore, a reduction strategy since their poor control of classical Arabic, the form of language they were supposed to use in interpretation, led them to switch to colloquial Arabic, which is easier to handle since they have a better control of it. Moreover, their knowledge of this form is both automatic and spontaneous, and switching to it in interpretation requires much less awareness of language use than is the case when employing classical Arabic. 
Variability, therefore, is accounted for in the dichotomy between spoken and standard Arabic or, in other words, between the interpreter's language behavior when monitoring and when not monitoring.

\section{Conclusion and Recommendations}

As we have indicated earlier, the findings of the study, which are based on the two data sources - the questionnaire responses and the actual interpretation recordingsshowed that the majority of respondents and interpreters seem to be more comfortable when interpreting from Arabic into English than vice versa. We are, therefore, inclined to conclude that it may not always be the case that people generally perform the same task (in speaking or in interpreting) less well in a second language than in a first.

Our findings lead us to agree with Lederer (1978: 327), who states that "understanding is not the only process of the human mind that can be studied in interpretation." As she points out, "The interpreter is not only a listener, he is also a speaker." $\mathrm{He}$ is not the message, but he is the means to conveying the intended message. This requires from the interpreter a good control of the different styles, content, register, the art of speaking, and so on. Therefore, the interpreter is hardly given enough time to think and has to "put across" immediately and as accurately as possible whatever a speaker wishes to convey. He, therefore, has to acquire these two basic processes: understanding and speaking, and to be able to transfer smoothly between them.

In light of the findings of the present study, which are contrary to the theoretical argument discussed above regarding the claim for interpreters working better into a dominant (native) language, we believe that more studies are needed in this direction in order to confirm or prove the findings of this study.

As a matter of fact, few studies have confirmed the results of our study. Lambert (1978), for example, reported that several bilinguals showed dominance in their second language over their native, mother language. The bilinguals he studied were American graduate students who were in several cases revealing a relative dominance of French or Italian over English on different test batteries (p. 134).

Another point in favor of our findings is that the differences in language use in registers found in colloquial, standard, and classical Arabic - as opposed to the relative similarity of language in different registers in English-may lead interpreters to feel more comfortable working from Arabic into English.

Finally, the background of the interpreter vis-à-vis the subject matter of the presentation being interpreted is another important variable which could be investigated more fully through further research. For example, a person trained in linguistics may have difficulty with presentations on economics, and a political scientist may not be able to handle discussions of linguistics.

\section{NOTE}

We are grateful to Dr. Donland Lance, Professor Emeritus of Linguistics, University of Missouri, USA, who read and made critical remarks on earlier drafts of this paper. We assume complete responsibility for the shortcomings of this paper. 


\section{REFERENCES}

AL-Khanji, R. (1996): “Two Perspectives in Analyzing Communication Strategies,” in IRAL, 34/2, pp. 144-154.

Al-Khanji, R., El-Shiyab, S. and R. Hussein (2000): "On the Use of Compensatory Strategies in Simultaneous Interpretation,” in META, 45/3, pp. 548-557.

Bialystok, E. (1984): “Strategies in Interlanguage Learning and Performance." In Alan Davies, C. Criper and A. P. R. Howatt (eds.), Interlanguage. Edinburgh: Edinburgh University Press, 37-48.

Ellis, R. (1984): "Communication Strategies and the Evaluation of Communicative Performance," in ELT Journal 38/1:39-44.

Frawley, W. and J. P. Lantolf (1985): “Second Language Discourse: A Vygotskyan Perspective," in Applied Linguistics, 6/11:19-44.

Herbert, J. (1978): “How Conference Interpretation Grew." In, D. Gerver and H. Sinaiko (eds.), Language Interpretation and Communication. New York/London: Plenum Press, pp. 5-10.

Jakendoff, R. (1972): Semantic Interpretation in Generative Grammar. Cambridge: MIT Press.

Krashen, S. (1981): Second Language Acquisition and Second Language Learning. Oxford: Pergamon.

Labov, W. (1969): “The Study of Language in its Social Context," in Studium Generale 23:30-87.

LAmbert, W. (1978): "Psychological Approaches to Bilingualism, Translation and Interpretation." In D. Gerver and H. Sinaiko (eds.), Language Interpretation and Communication. New York/ London: Plenum Press, pp. 131-142.

Lederer, M. (1978): "Simultaneous Interpretation-Units of Meaning and other Features." In D. Gerver and H. Sinaiko (eds.), Language Interpretation and Communication. New York/ London: Plenum Press, pp. 323-333.

QIan, H. (1994): "Looking at Interpretation from a Communicative Perspective," in Babel 40/4, pp. 214-221.

Qzar, M. H. (1997): The Role of Memory as a Cognitive Psychological Faculty in Simultaneous Interpretation. Unpublished M.A. Thesis, Yarmouk University, Jordan.

Saville, M. and Hargraves (1999): “Assessing Speaking in the Revised FCE," in ELT Journal, 53/ 1, pp. $42-51$.

SchwedA-Nicholson, N. (1992): "Linguistic Theory and Simultaneous Interpretation: Semantic and Pragmatic Considerations.” Babel, Vol. 38:2, pp. 90-100.

Seleskovitch, D. (1978): “Language and Cognition.” In D. Gerver and H. Sinaiko (eds.), Language Interpretation and Communication. New York/London: Plenum Press, pp. 333-341.

Tarone, E. (1981): "Some Thoughts on the Notion of Communication Strategy." TESOL, Vol. 15, pp. 285-295.

Uhlenbeck, F. M. (1978): “On the Distinction between Linguistics and Pragmatics.” In D. Gerver and H. Sinaiko (eds.), Language Interpretation and Communication. New York/London: Plenum Press, pp. 185-197.

Vygotsky, L. S. (1962): Thought and Language. Cambridge, Mass: MIT Press. 


\section{APPENDIX}

This study seeks to establish whether or not interpreters are better off when decoding/interpreting oral discourse from a foreign language (i.e., English) into their native tongue (i.e., Arabic).

Please answer each of the following questions by putting a $(\boldsymbol{})$ mark in the appropriate box. Thank you.

\begin{tabular}{|c|c|c|}
\hline & Arabic & English \\
\hline $\begin{array}{l}\text { 1. As an interpreter I maintain adequate time lag when I } \\
\text { interpret into }\end{array}$ & & \\
\hline 2. My switch mechanism is at its best when I interpret into & & \\
\hline $\begin{array}{l}\text { 3. I have better oral fluency in terms of quality and time when } \\
\text { I interpret into }\end{array}$ & & \\
\hline $\begin{array}{l}\text { 4. More omission (i.e., loss of information) occurs when I } \\
\text { interpret into }\end{array}$ & & \\
\hline $\begin{array}{l}\text { 5. Strategies of anticipation are best achieved when I interpret } \\
\text { into }\end{array}$ & & \\
\hline 6. I feel less tense in front of an audience when I interpret into & & \\
\hline 7. When speakers talk fast I prefer to interpret into & & \\
\hline $\begin{array}{l}\text { 8. I can better cope with listening and speaking when I } \\
\text { interpret into }\end{array}$ & & \\
\hline $\begin{array}{l}\text { 9. I can have a better short-term memory when I interpret } \\
\text { into }\end{array}$ & & \\
\hline 10. I can resist tension more when I interpret into & & \\
\hline 11. I feel more grammar conscious when I interpret into & & \\
\hline $\begin{array}{l}\text { 12. Note-taking and recapitulating can be achieved more easily } \\
\text { when I interpret into }\end{array}$ & & \\
\hline $\begin{array}{l}\text { 13. I feel more irritated at the mistakes I may make when I } \\
\text { interpret into }\end{array}$ & & \\
\hline $\begin{array}{l}\text { 14. I may resort to non-standard slang when I cannot immedi- } \\
\text { ately find a TL equivalent when I interpret into }\end{array}$ & & \\
\hline $\begin{array}{l}\text { 15. Transfer strategies are hampered by syntactic demands when } \\
\text { I interpret into }\end{array}$ & & \\
\hline
\end{tabular}

